\title{
INSECT DAMAGED WOOD AS A SOURCE OF REINFORCING FILLER FOR THERMOPLASTIC COMPOSITES
}

\author{
Türker Güleç', Mürşit Tufan ${ }^{2, \star}$, Selçuk Akbaş ${ }^{3}$
}

\begin{abstract}
In this study, wood polymer composites were manufactured using insect damaged Eastern Black Sea Fir (A. Nordmanniana) wood as filler. The effects of wood type (sound vs insect damaged) and presence of coupling agent ( $0 \%$ vs $3 \%)$ on the flexural, tensile, impact, thermal and morphological properties of the wood polymer composites were investigated. The mechanical property values of the wood polymer composites specimens decreased when insect damaged wood was used as filler than sound wood, except for the impact strength values. Flexural, tensile and impact strength values, insect damaged wood filled with coupling agent composites provided higher values compared to sound wood filled without coupling agent composites. However, addition of maleic anhydride-graftedpolyethylene coupling agent into polymeric matrix improved both sound and insect damaged filled composite properties. Thermogravimetric analysis analysis showed two main decomposition peaks for polymer composites. Compared to unfilled high-density polyethylene, addition of both sound and insect damaged wood reduced decomposition peak but increased the residue due to the charring of the wood. The results of differential scanning calorimeter analysis showed that addition of sound or insect damaged wood in polymer matrix increase the crystallinity compared the unfilled high-density polyethylene due to the nucleating effect of the filler. Among the composite maleic anhydride-graftedpolyethylene modified composites provided higher crystallinity than unmodified ones.
\end{abstract}

Keywords: Compression moulding, electron microscopy, mechanical properties, polymer, thermal analysis.

\section{INTRODUCTION}

The uses of wood plastic composites (WPCs) were extensively increased over the years due to their outstanding properties such as enhanced strength, stiffness, creep resistance and high dimensional stability. Their market share has grown dramatically with an average annual growth rate of near $18 \%$ in Northern America and 14\% in Europe (Wang et al. 2007, Ashori 2008).

WPCs can be manufactured using various lignocellulosic materials such as wood species like pine, poplar, maple, oak, etc. and agricultural wastes like corncobs, nutshell, pepper stem, cereal straw as a filling material. Lignocellulosic materials provide several advantages such as being lightweight, having a low density, low cost, high specific properties, low energy consumption generation of a rural/ agricultural-based economy. (Nitin and Singh 2013, Mengeloglu and Karakus 2008, Panthapulakkal et al. 2006, Mengeloglu and Matuana 2003, Clemons 2002, Bledzki and Gassan 1999). As polymeric matrices, WPCs can utilize several different thermoplastic polymers such as polyethylene, polypropylene, and polyvinyl chloride. Since lignocellulosic materials are hydrophilic in nature, its

\footnotetext{
${ }^{1}$ Artvin Coruh University, Faculty of Forestry, Wood Products Chemistry and Technology, Artvin, Turkey.

${ }^{2}$ Artvin Çoruh University, Faculty of Forestry, Forest Biology and Wood Protection Technology, Artvin, Turkey.

${ }^{3}$ Forest Industry Engineer (PhD), Forest Biology and Wood Protection Technology, Turkey.

•Corresponding author: mtufan35@hotmail.com
}

Received: 13.11.2015 Accepted: 17.11.2016 
compatibility with hydrophobic polymeric material is reduced, so the use of coupling agent is generally required during composite preparation. The mechanical properties values are greatly improved by the addition of coupling agent. This behavior is attributed to the reaction of the hydrophilic $\mathrm{OH}$ groups of the filler and the acid anhydride groups of the coupling agent, as it has been proposed in the literatüre (Adhikary 2008, Lee and Kim 2009, Ayrilmis et al. 2010). The anhydride groups in the coupling agent enter into an esterification reaction with the surface hydroxyl groups of lignocellulosic materials and covalently bond to the hydroxyl groups (Adhikary 2008). The coupling agent improves the interfacial adhesion between lignocellulosic materials and polymer matrix, leading to less microvoids and fiberpolymer debondings in the interphase region (Klyosov 2007, Li 2012).

Abies nordmanniana ssp. (Eastern Black Sea Fir) is a naturally grown tree species in Turkey and covers approximately 0,6 million ha of Turkish forests. Eastern Black Sea Fir log has a high economic value since they have utilised for several industrial applications. However, in recent years considerable amount of tress were damaged by Pityokteines curvidens (Germ.) and resulted in a significant wealth lost due to the damages on wood material. One million cubic meter trees were damaged by this insect only in 2008 (Atesoğlu et al. 2014, Serin and Güleç 2014). Damaged Abies nordmanniana ssp. wood had a different chemical characteristics; Serin and Güleç (2014) reported that the holocellulose quantity is seen to be $73,88 \%$ in sound woods compared to $70,08 \%$ in insect damaged woods. Likewise, $\alpha$-cellulose quantity was found to be higher in the sound wood, also lignin and ash content of the insect damaged woods had a higher than the sound woods. These changes can effect mechanical properties of WPCs since wood species and its characteristics have a significant influence on WPCs properties (Maldas et al. 1989).

The aim of this study was to investigate the utilisation of damaged Eastern Black Sea Fir $(A$. nordmanniana) wood in the manufacture of high-density polyethylene (HDPE) based wood plastic composites and to determine their mechanical and thermal properties and changes in their morphology.

\section{MATERIALS AND METHODS}

\section{Materials}

High density polyethylene (HDPE-SO 464) by PETKIM and maleic anhydrite grafted polyethylene (Licocene PEMA 4351) by Clariant were used as polymeric matrix and coupling agent, respectively. Wood flour produced from undamaged Eastern Black Sea Fir (A. nordmanniana) wood and damaged by Pityokteines curvidens (Germ.) were used as organic filler and coded as sound (S) and insect damaged (ID), respectively. For the study, S and ID wood were grounded using a Wiley Mill and were screened to $0,25-0,40 \mathrm{~mm}$ sizes (passing 40 mesh sizes and staying on 60 mesh size screens). Before the WPC production, the wood flour was dried in a laboratory oven at $103 \pm 2{ }^{\circ} \mathrm{C}$ for $24 \mathrm{~h}$ to a moisture content of $0-1 \%$ based on the oven-dry weight of wood.

\section{Manufacturing of thermoplastic composites through compression molding}

HDPE, sound (S) or insect damaged (ID) flour and maleic anhydride-grafted-polyethylene (MAPE) granulates were processed using single-screw extruder (RONDOL 3212) depending on the formulation presented in Table 1. The four-barrel temperature zones of the extruder were controlled at 175 and 190 ${ }^{\circ} \mathrm{C}$. The extruded strands were passed through a water bath and subsequently pelletized. Finally, pellets were compression molded in the hot press for 3 minutes at $175^{\circ} \mathrm{C}$ and $10 \mathrm{MPa}$ pressure. 
Table 1. Formulations of composites.

\begin{tabular}{|c|c|c|c|c|}
\hline Group ID & $\begin{array}{c}\text { S } \\
(\mathbf{w t} \%)\end{array}$ & $\begin{array}{c}\text { ID } \\
(\mathbf{w t} \%)\end{array}$ & $\begin{array}{c}\text { HDPE } \\
(\mathbf{w t} \%)\end{array}$ & $\begin{array}{c}\text { MAPE } \\
(\mathbf{w t} \%)\end{array}$ \\
\hline A & 50 & - & 50 & - \\
\hline B & 50 & - & 47 & 3 \\
\hline C & - & 50 & 50 & - \\
\hline D & - & 50 & 47 & 3 \\
\hline
\end{tabular}

\section{Determination of Mechanical Properties}

The flexural and tensile properties of all samples were determined according to ASTM D790 and ASTM D638, respectively, using a Zwick 10KN Universal Testing Machine (Zwick Inc. Germany). The Izod impact strengths were determined according to ASTM D256 using a HIT5.5P Testing Machine manufactured by Zwick Inc. All samples were notched in the centre according to the standard using a Polytest notching cutter by RayRan ${ }^{\mathrm{TM}}$. Seven samples for each group were tested.

\section{Thermogravimetric Analysis and Differential Scanning Calorimetry}

The thermogravimetric analysis (TGA) of each type of WPC was carried out in an inert environment of gas nitrogen flowing $20 \mathrm{~mL} / \mathrm{min}$ using a PerkinElmer STA 6000 analyzer. The specimens having a weight between $17 \mathrm{mg}$ and $20 \mathrm{mg}$ were heated from 50 to $600{ }^{\circ} \mathrm{C}$ at a heating rate of $20^{\circ} \mathrm{C} / \mathrm{min}$. The corresponding weight loss (\%) and its derivative weight loss ( $\mathrm{min} / \%)$ were recorded.

Melting and crystallization behaviour of the WPCs were studied in a heat-flux type differential scanning calorimeter (DSC) (PerkinElmer DSC 8000) according to ASTM D3418 (2008). To determine the influence of the increasing amount of the decayed wood or sound wood on the thermal properties of WPC, test sample of 5-6 mg of each type of WPC was placed in an aluminium pan and then heated from 35 to $250{ }^{\circ} \mathrm{C}$ at a heating rate of $10^{\circ} \mathrm{C} / \mathrm{min}$ under the nitrogen flow.

\section{Scanning Electron Microscopy}

The fractured surface of each sample was studied using a JEOL scanning electron microscope (SEM) (Jeol/Neoscope Jcm-5000). The sample was first dipped into liquid nitrogen and then was broken into half. Finally, broken sample with clean surfaces was coated with gold to provide electrical conductivity.

\section{RESULTS AND DISCUSSION}

In this study, the effect of filler type (S vs ID) and coupling agent on the mechanical and thermal properties of HDPE based wood composites were investigated. Mechanical properties and thermal properties were discussed in separate sections.

\section{Mechanical Properties}

The effects of filler type and MAPE modification on tensile, flexural and impact properties were presented in Table 2 and in Figure 1-2-3-4-5. In these figures, composites produced with sound wood (S) and insect damaged wood (ID) were shown with small triangles and small squares, respectively. Statistical analysis showed that filler type (S vs ID) and MAPE amount ( 0 vs $3 \%$ ) significantly affected the tensile and flexural strength of the produced composites $(\mathrm{p}<0,0001)$. Without MAPE modification, sound wood (S) filled composites provided significantly higher tensile and flexural strength compared to insect damaged wood (ID) filled ones. Chemical composition of S and ID Eastern Black Sea Fir (A. nordmanniana) wood was studied by Serin and Güleç (2014) and some differences were determined. 
Cellulose and hemicellulose amount found in ID wood was lower than S wood. According to Shebani et al. (2009) high cellulose rate materials with the filled of composite provide higher mechanical properties (tensile, flexural, impact etc.) when compared to low cellulose rate. When MAPE coupling agent was present in the matrix, these properties were significantly improved for both S and ID filled composites. Most of mechanical properties of polymer composites depend on mainly interaction developed between lignocellulosic filler and the thermoplastic material. One way to improve this interaction is incorporating a coupling agent as an additive. In general, the additives help the compatibility between hydrophilic wood and hydrophobic plastic allowing the formation of single-phase composite (Wechsler and Hirizoglu 2006).

Table 2. Mechanical properties of sound (S) and insect damaged (ID) Fir wood flour filled unmodified and MAPE modified HDPE composites.

\begin{tabular}{|c|c|c|c|c|c|}
\hline $\begin{array}{c}\text { Composite } \\
\text { code* }\end{array}$ & $\begin{array}{c}\text { Flexural } \\
\text { Strength } \\
\mathbf{( M P a )}\end{array}$ & $\begin{array}{c}\text { Flexural } \\
\text { Modulus } \\
\mathbf{( G P a )}\end{array}$ & $\begin{array}{c}\text { Tensile } \\
\text { Strength } \\
\mathbf{( M P a )}\end{array}$ & $\begin{array}{c}\text { Tensile } \\
\text { Modulus } \\
\mathbf{( G P a )}\end{array}$ & $\begin{array}{c}\text { Impact } \\
\text { Properties } \\
\mathbf{( J / m )}\end{array}$ \\
\hline $\mathbf{A}$ & 29,27 & 2,23 & 15,30 & 0,96 & 43,65 \\
& $(1,21)$ & $(0,26)$ & $(1,61)$ & $(0,09)$ & $(1,38)$ \\
\hline \multirow{2}{*}{$\mathbf{B}$} & 33,20 & 2,39 & 19,11 & 1,80 & 54,30 \\
& $(2,67)$ & $(0,21)$ & $(0,69)$ & $(0,15)$ & $(2,85)$ \\
\hline \multirow{2}{*}{$\mathbf{C}$} & 22,31 & 1,96 & 10,09 & 0,74 & 43,04 \\
& $(2,05)$ & $(0,32)$ & $(1,66)$ & $(0,05)$ & $(1,93)$ \\
\hline \multirow{2}{*}{$\mathbf{D}$} & 33,94 & 2,22 & 17,92 & 0,86 & 49,02 \\
& $(10,4)$ & $(0,26)$ & $(0,89)$ & $(0,07)$ & $(1,32)$ \\
\hline
\end{tabular}

-The numerical value in the parenthesis is standard deviation.

-Each value is the average of seven samples tested.

-*See Table 1 for composite formulation

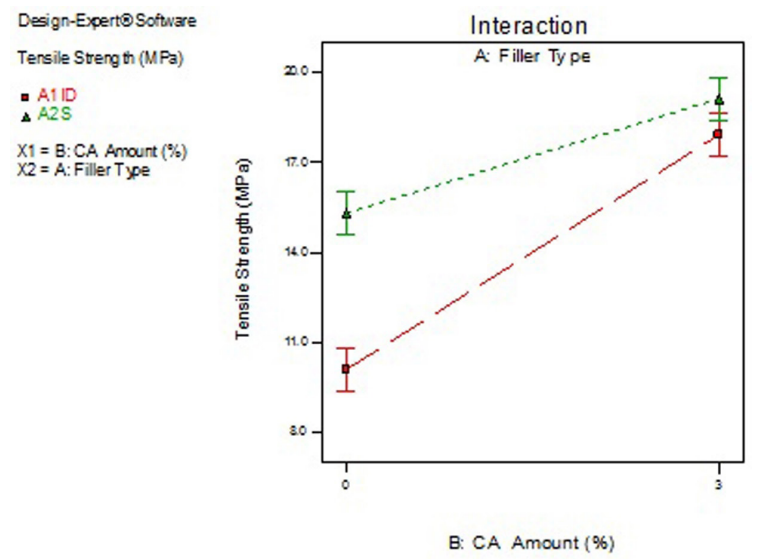

Figure 1. The effect of filler type and MAPE modification on tensile strength of produced composites. 


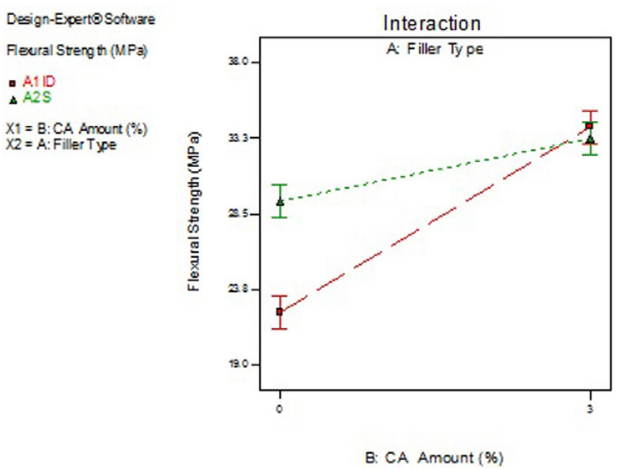

Figure 2. The effect of filler type and MAPE modification on flexural strength of produced composites

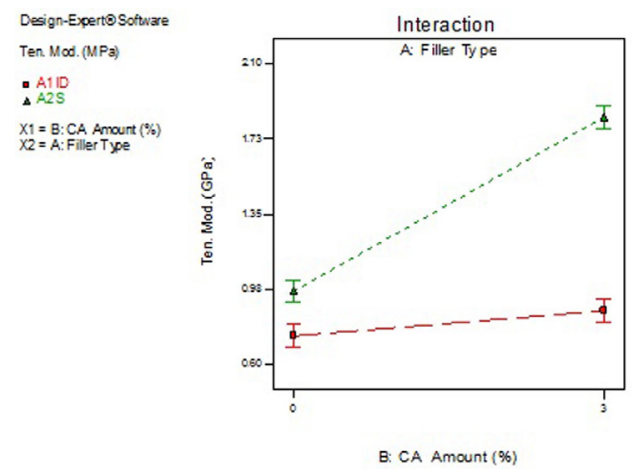

Figure 3. The effect of filler type and MAPE modification on tensile modulus of produced composites.

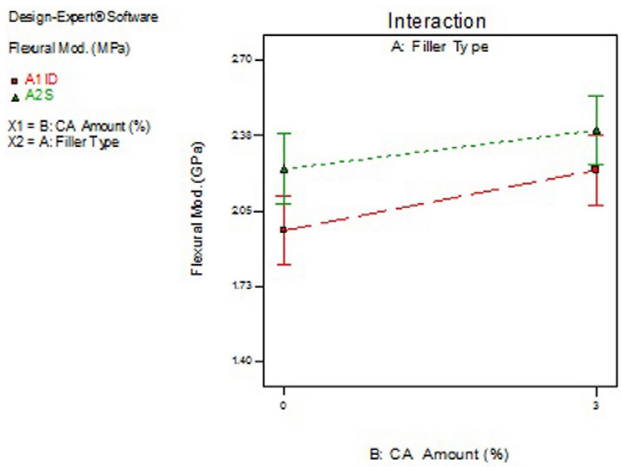

Figure 4. The effect of filler type and MAPE modification on flexural modulus of produced composites. 


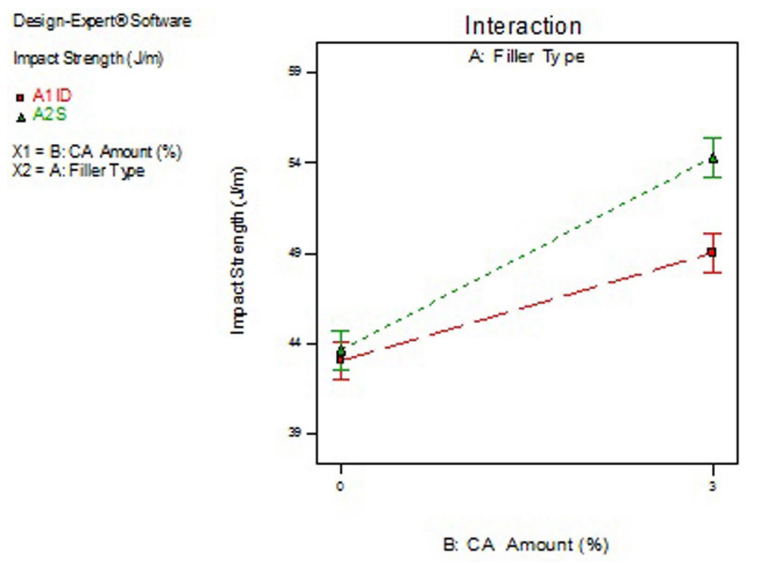

Figure 5. The effect of filler type and MAPE modification on impact strength of produced composites.

In the case of tensile and flexural modulus, there is a statistically significant difference between composites filled S wood and ID wood. Similar to strength properties, S wood filled composites provided higher values compared to ID wood filled composites. Once again regardless of filler type, addition of MAPE coupling agent significantly improved the modulus and strength values of the composites (Kordkheili et al. 2013, Kaymakci and Ayrilmis 2014). It should be noted that even in composite having MAPE, S wood filled composites provided higher properties than ID wood filled ones.

The effect of filler type and MAPE modification on impact strength of S wood and ID wood filled composites was also studied. Result showed that without MAPE modification, there is no significant difference between impact strength of S wood and ID wood filled composites. Addition of MAPE has significantly improved impact strength of both composite types (Moreno et al. 2013, Tufan et al. 2015). This improvement was more pronounced in composites filled with $\mathrm{S}$ wood.

Addition of MAPE coupling agent has improved all mechanical properties. This is usually caused by the improved compatibility between hydrophobic polymeric matrix and hydrophilic filler and better dispersion of filler in the matrix (Chen et al. 2015). Changes on the morphology of composites were investigated using SEM images. Figure 6 and Figure 7 shows SEM images of unmodified and MAPE modified composite samples. Holes caused by pulled out fiber and standing fiber in groups A and C can be seen in Figure 6. This is an indication of poor surface adhesion between matrix and filler of the WPC samples. Figure 7 shows good surface adhesion resulting from the addition of $3 \%$ MAPE in groups B-D. The poor encapsulation between the lignocellulosic material and polymer matrix was indicated with arrows in Figure 6. Wood particles which have not separated out but are dispersed in the polymer matrix are shown in Figure 7. This has indicated good encapsulation between the lignocellulosic material and polymer matrix. 

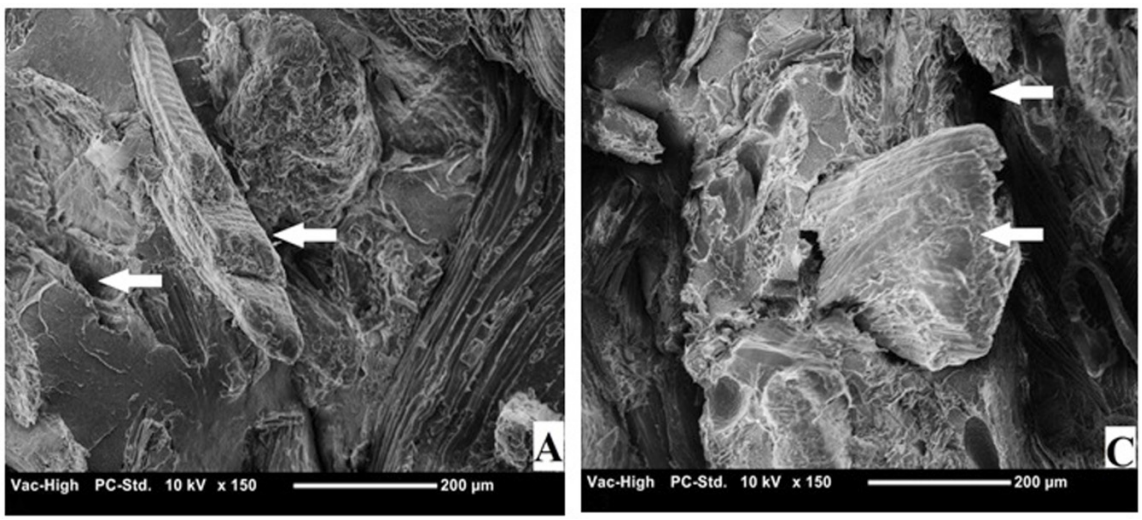

Figure 6. SEM images of samples without MAPE coupling agents (magnification x150 and scale

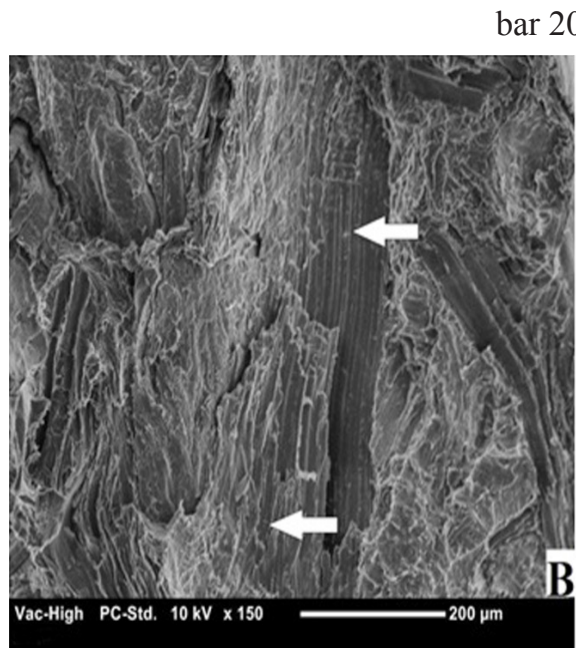
bar $200 \mu \mathrm{m})$.

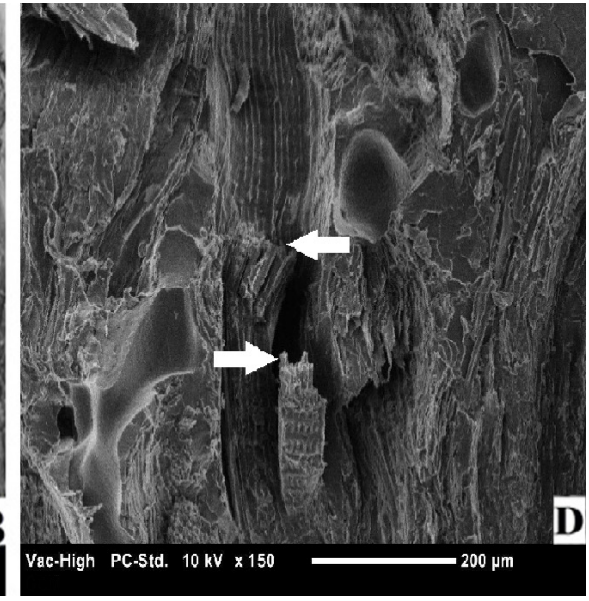

Figure 7. SEM images of samples with MAPE coupling agents (magnification x150 and scale bar $200 \mu \mathrm{m})$.

\section{Thermogravimetric analysis (TGA) and Differential scaning calorimetry (DSC) results}

The thermal decomposition of polymer composites was studied using TGA and their thermographs are presented in Figure 8. For comparison, TGA thermographs of HDPE were also taken. Derivatives of TGA thermographs were calculated and given in Table 3. All composites displayed similar two major weight-loss regions. The first region was between $230{ }^{\circ} \mathrm{C}-390^{\circ} \mathrm{C}$ and the second was between $390{ }^{\circ} \mathrm{C}-510^{\circ} \mathrm{C}$. Wood is complex material and consist mainly of cellulose, hemicellulose, and lignin (Ndiaye and Tidjani 2012). Several studies have determined that the degradation temperatures of hemicelluloses, lignin and cellulose around 180, 200 and $210{ }^{\circ} \mathrm{C}$, respectively. During wood degradation, the temperatures in the range of $200-350^{\circ} \mathrm{C}$ is assigned to hemicellulose and cellulose degradation while $250-500^{\circ} \mathrm{C}$ to lignin degradation. Hemicellulose degradation starts at relatively low temperature because of acetyl groups in structure (Jeske et al. 2012, Deka and Maji 2010). 


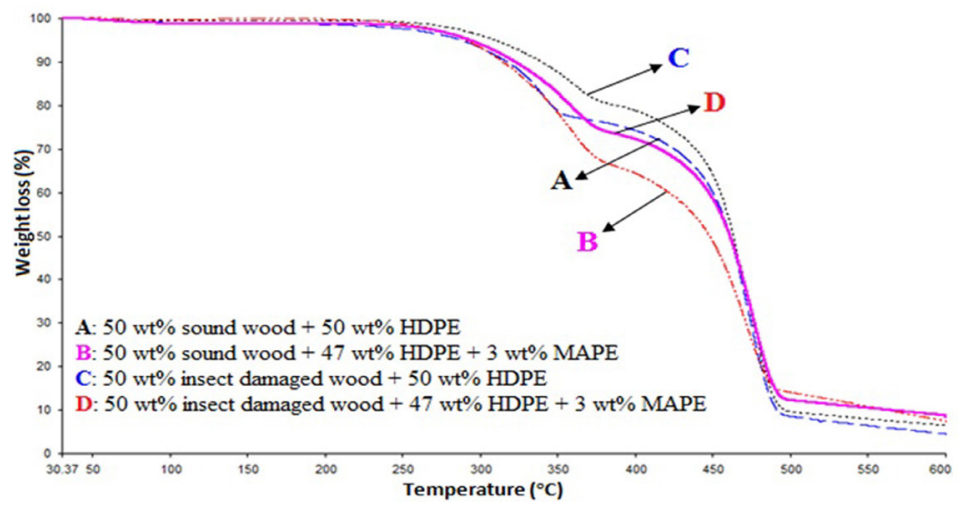

Figure 8. Curves of polymer composites (S: sound wood. ID: insect damaged wood. HDPE: polyethylene. MAPE: maleic anhydride-grafted PE).

In the case of HDPE, the highest decomposition temperature was reported to be around $450-480^{\circ} \mathrm{C}$ (Tascioglu et al. 2014, Mengeloglu and Kabakci 2008) reported that addition of lignocellulosic filler into thermoplastic matrix induced HDPE to degrade thermally at low temperatures. Similar trend was observed in our study since main decomposition peak of HDPE was reduced from $470^{\circ} \mathrm{C}$ to around $440-450^{\circ} \mathrm{C}$ for composites. When the residues of the samples at $500{ }^{\circ} \mathrm{C}$ were compared, HDPE and manufactured composites had 0,023-percent and around 8-12-percent residues, respectively. It is believed that addition of woody material into HDPE increased the remaining residues due to the charring of wood material (Mengeloglu and Kabakci 2008).

Table 3. The results of Thermogravimetric analysis (TGA).

\begin{tabular}{|c|c|c|c|c|c|c|c|}
\hline \multirow{2}{*}{$\begin{array}{c}\text { Composite } \\
\text { Code }\end{array}$} & \multicolumn{3}{|c|}{ 1st region } & \multicolumn{3}{|c|}{ 2nd region } & $\begin{array}{c}\text { Residue } \\
\text { at }\end{array}$ \\
\cline { 2 - 8 } & Range $\left({ }^{\circ} \mathrm{C}\right)$ & $\begin{array}{c}\text { Peak } \\
\left({ }^{\circ} \mathrm{C}\right)\end{array}$ & $\begin{array}{c}\text { Weight loss } \\
(\%)\end{array}$ & Range $\left({ }^{\circ} \mathrm{C}\right)$ & $\begin{array}{c}\text { Peak } \\
\left({ }^{\circ} \mathrm{C}\right)\end{array}$ & $\begin{array}{c}\text { Weight } \\
\text { loss }(\%)\end{array}$ & $\begin{array}{c}\mathbf{5 0 0}{ }^{\circ} \mathbf{C} \\
(\%)\end{array}$ \\
\hline HDPE & - & - & - & $416,7-495,47$ & 470,16 & 71,95 & 0,023 \\
\hline A & $230,88-390,43$ & 294,59 & 31,874 & $391,61-500,75$ & 448,65 & 63,455 & 8,551 \\
\hline B & $230,84-390,18$ & 297,89 & 22,490 & $391,30-505,66$ & 441,53 & 47,602 & 11,333 \\
\hline C & $230,28-390,44$ & 303,74 & 20,502 & $391,23-504,96$ & 448,10 & 58,133 & 9,706 \\
\hline D & $230,74-390,14$ & 295,34 & 17,487 & $391,71-504,67$ & 448,41 & 55,656 & 12,257 \\
\hline
\end{tabular}

The DSC results of the HDPE and polymer composites filled with S an ID wood were presented in Table 4. There were negligible change on the second melting peak temperature of the polymer composites. Similar values were observed for the first melting peak temperature and crystallization peak temperature of the composites. The second melting enthalpy $\left(\Delta \mathrm{H}_{\mathrm{m}}\right)$ of the $\mathrm{S}$ wood filled composites with and without coupling agent increased from $79,7 \mathrm{~J} / \mathrm{g}$ to $96,9 \mathrm{~J} / \mathrm{g}$. These values were determined that $78,5 \mathrm{~J} / \mathrm{g}$ to $90,4 \mathrm{~J} / \mathrm{g}$ for ID wood filled composites with and without coupling agent respectively. The crystallization degree $\left(\mathrm{X}_{\mathrm{c}}\right)$ of the polymer in the composites showed a similar trend to the results of $\Delta \mathrm{H}_{\mathrm{m}}$ The $\mathrm{X}_{\mathrm{c}}$ values of the polymer composites produced from S and ID wood were found 54,4 and 53,5 . These values increased 66,1 and 61,7 by adding coupling agent respectively. When crystallinity of the polymer composite is compared to HDPE crystallinity, it can be seen that there is big jump on crystallinity. This increase might be due to the nucleating effect of wood flour in the matrix. Similar results were also reported by others (Mathewi et al. 2006, Pilla et al. 2008, Quillin et al. 1993). The coupling agent provides better dispersion and due to the chain branching of MA in the polymer composites (Ndiaye and Tidjani 2012). 
Table 4. The results of differential scanning calorimetry (DSC) analysis.

\begin{tabular}{|c|c|c|c|c|c|c|c|}
\hline $\begin{array}{c}\text { Composite } \\
\text { code }\end{array}$ & $\begin{array}{c}\mathbf{T m}^{\mathbf{1}} \\
\left.\mathbf{(}^{\mathbf{}} \mathbf{C}\right)\end{array}$ & $\begin{array}{c}\mathbf{T c}^{\mathbf{1}} \\
\left.\mathbf{(}^{\mathbf{}} \mathbf{C}\right)\end{array}$ & $\begin{array}{c}\mathbf{T c}^{\mathbf{2}} \\
\left({ }^{\mathbf{}} \mathbf{C}\right)\end{array}$ & $\begin{array}{c}\mathbf{\Delta H c} \\
(\mathbf{J} / \mathbf{g})\end{array}$ & $\begin{array}{c}\mathbf{T m}^{\mathbf{2}} \\
\left({ }^{\mathbf{}} \mathbf{C}\right)\end{array}$ & $\begin{array}{c}\mathbf{\Delta H m} \\
(\mathbf{J} / \mathbf{g})\end{array}$ & $\begin{array}{c}\mathbf{X c} \\
(\mathbf{\%})\end{array}$ \\
\hline HDPE & 131,68 & 120,13 & 115,90 & 128,68 & 134,70 & 136,27 & 46,5 \\
\hline A & 135,5 & 119,8 & 116,6 & 81,2 & 135,7 & 79,7 & 54.4 \\
\hline B & 136,0 & 119,7 & 116,3 & 94,5 & 136,7 & 96,9 & 66.1 \\
\hline $\mathbf{C}$ & 135,6 & 119,7 & 116,5 & 79,0 & 135,7 & 78,5 & 53.5 \\
\hline D & 136,4 & 119,6 & 116,3 & 86,5 & 136,5 & 90,4 & 61.7 \\
\hline
\end{tabular}

$\mathbf{T m}^{1}$ : Peak temperature of first melting, $\mathbf{T c}^{\mathbf{1}}$ : Onset temperature of crystallization.

$\mathbf{T c}^{2}$ : Peak temperature of crystallization, $\Delta \mathbf{H} \mathbf{c}$ : Enthalpy of crystallization.

$\mathbf{T m}^{2}$ :Peak temperature of second melting, $\Delta \mathbf{H m}$ : Enthalpy of second melting.

Xc: Crystallization degree.

\section{CONCLUSIONS}

Based on the results of this study the following conclusions can be drawn.

The mechanical properties of produced from $\mathrm{S}$ wood flour composites were better than produced from ID wood flour composites.

The addition of MAPE in ID wood flour composites mechanical properties were significantly increased and showed same value with $\mathrm{S}$ wood flour composites.

Low economic value ID wood can be utilized in the manufacture of WPC to improve their economic value.

\section{REFERENCES}

Adhikary, K.B., 2008. Development ofwood flour recycled polymer composite panels as building materials. Ph.D. Thesis, University of Canterbury, Christchurch, New Zeland, 229p.

Ashori, A. 2008. Wood-plastic composites as promising green-composites for automotive industries. Bioresources Technology 99:4661-4667.

ASTM D 256. 2002. Determining the Izod Pendulum Impact Resistance of Plastics. American society for Testing and Materials. West Conshohocken (PA).

ASTM D 638. 2004. Standard Test Method for Tensile Properties of Plastics., American society for Testing and Materials. West Conshohocken (PA). 08 (01).

ASTM D 790 2004. Flexural Properties of Unreinforced and Reinforced Plastics and Electrical Insulating Materials. American society for Testing and Materials. West Conshohocken (PA).08 (01).

ASTM D3418. 2008. ASTM International, Standard test method for transition temperatures and enthalpies of fusion and crystallization of polymers by differential scanning calorimetry. American society for Testing and Materials. West Conshohocken (PA). 
Ateşoğlu, A.; Tunay, M.; Kaygın, T.A.; Yıldız, Y.; Kavaklı, Z. 2014. Analysis and query of the damages resulted from fir bark beetle in gis environment within forests of Zonguldak-Ulus forestry department. $2^{\text {nd }}$ Symp of Turkey Forest Ent and Path Symp Proceed 157-164.

Ayrilmis, N., Buyuksari, U., Dundar, T. 2010. Waste pine cones as a source of reinforcing fillers for thermoplastic composites. J Appl Polym Sci 117:2324-2330.

Bledzki, A.K.; Gassan, K. 1999. Composites reinforced with cellulose based fibres. Progress in Polymer Science 24:221-274.

Chen, R.S.; Ghani, M.H.A.; Ahmad, S.; Salleh, M.N.; Tarawneh, M.A. 2015. Rice husk flour biocomposites based on recycled high-density polyethylene/polyethylene terephthalate blend:effect of high filler loading on physical, mechanical and thermal properties. Journal of Composites Materials 49(10):1241-1253.

Clemons, C. 2002. Wood-plastic composites in the United States: the interfacing of two industries. Forest Products Journal 52:10-18.

Deka, B.K.; Maji, T.K. 2010. Effect of coupling agent and nanoclay on properties of HDPE, LDPE, PP, PVC blend and Phargamites karka nanocomposite. Composites Science and Technology 70: $1755-1761$.

Jeske, H.; Schirp, A.; Cornelius, F. 2012. Development of a thermogravimetric analysis (TGA) method for quantitative analysis of wood flour and polypropylene in wood plastic composites (WPC). Thermochimica Acta 543:165-171.

Kaymakci, A.; Ayrilmis, N. 2014. Investigation of correlation between Brinell hardness and tensile strength of wood plastic composites. Composites: Part B 58:582-585.

Klyosov, A.A. 2007. Wood-Plastic Composites. John Wiley \& Sons, Hoboken, NJ, 702p.

Kordkheili, H.Y.; Farsi, M.; Rezazadeh, Z. 2013. Physical, mechanical and morphological properties of polymer composites manufactured from carbon nanotubes and wood flour. Composites: Part B 44:750-755.

Lee, H.; Kim, S.D. 2009. Preparation and Physical Properties of Wood/Polypropylene/Clay Nanocomposites. Journal of Applied Polymer Science, Vol. 111:2769-2776.

Li, Y. 2012. Effect of Coupling Agent Concentration, Fiber Content, and Size on Mechanical Properties of Wood/HDPE Composites. International Journal of Polymeric Materials and Polymeric Biomaterials 61(11):882-890.

Maldas, D.; Kokta, B.V.; Deneault, C. 1989. Influence of coupling agents and treatments on the mechanical properties of cellulose fiber-polystyrene composites. Journal of Applied Polymer Sciences $38: 413-439$.

Mathewi, A.P.; Oksman, K.; Sain, M. 2006. The effect of morphology and chemical characteristics of cellulose reinforcements on the crystallinity of polylactic acid. Journal of Applied Polymers Science 101(1):300-310. 
Mengeloglu, F.; Kabakci, A. 2008. Determination of thermal properties and morphology of eucalyptus wood residue filled high density polyethylene composites. International Journal of Molecular Sciences 9(2):107-119.

Mengeloglu, F.; Karakuş, K. 2008. Some properties of eucalyptus wood flour filler recycled high density polyethylene polymer-composites. Turkish Journal of Agriculture and Forestry 32:537-546.

Mengeloglu, F.; Matuana, L.M. 2003. Mechanical properties of extrusion foamed rigid pvc/ wood-flour composites. Journal of Vinyl and Additive Technology 9:26-31.

Moreno, P.; Rodrigue, D.; Giroux, Y.; Ballerini, A.; Gacitua, W. 2013. Morphological and mechanical caracterization of recyceled thermoplastic foams reinforced with wood sub-products. Maderas-Ciencia y Tecnologia 15(1):3-16.

Ndiaye, D.; Tidjani, A. 2012. Effects of coupling agents on thermal behavior and mechanical properties of wood flour/polypropylene composites. Journal of Composites Materials 46(24):30673075.

Nitin, S.; Singh, V.K. 2013. Mechanical behavior of walnut reinforced composite. Journal of Material Science and Environmental Science 4(2):233-238.

Panthapulakkal, S.; Zereshkian, A.; Sain, M. 2006. Preparation and characterization of wheat straw fibers for reinforcing application in injection molded thermoplastic composites. Bioresources Technology 97:265-272.

Pilla, S.; Gong, S.; O’Neill, E.; Rowell, R.M.; Krzysik, A.M. 2008. Polylactide-pine wood flour composites. Polymer Engineering and Science 48(3):578-587.

Quillin, D.; Caulfield, D.F.; Koutsky, J.A. 1993. Crystallinity in the polypropylene/cellulose system: I. Nucleation and crystalline morphology. Journal of Applied Polymers Science 50(7):11871194.

Serin, O.Z.; Güleç, T. 2014. Effects of pityokteines curvidens on the chemical composition of abies nordmanniana ssp. Nordmanniana. 2nd Symp of Turkey Forest Ent and Path Symp Proceed 268271.

Shebani, A.N.; Reenen, V.; Meincken, M. 2009. The effect of wood species on the mechanical and thermal properties of wood-LDPE composites. Journal of Composites Materials 43(11):13051318.

Tascioglu, C.; Tufan, M.; Yalcin, M.; Sen, S. 2014. Determination of biological performance, dimensional stability, mechanical and thermal properties of wood-plastic composites produced from recycled chromated copper arsenate-treated wood. Journal of Thermoplast Composites Materials 1-19. DOI: $10.1177 / 0892705714565704$.

Tufan, M.; Akbaş, S.; Güleç, T.; Taşçığlu, C.; Alma, M.H. 2015. Mechanıcal, Thermal, Morpological Properties And Decay Resistance Of Filled Hazelnut Husk Polymer Composites. Maderas-Ciencia y Tecnologia 17(4):865-874. 
Wang, Y.C.; Wong, P.M.H.; Kodur, V. 2007. An experimental study of the mechanical properties of fibre reinforced polymer (FRP) and steel reinforcing bars at elevated temperatures. Composite Structures 80:131-140.

Wechsler, A.; Hiziroglu, S. 2006. Some of the properties of wood-plastic composites. Journal of Building and Environment 42:2637-2644. 